Bandeirola com Detalhe em forma de folha de trevo (1581).

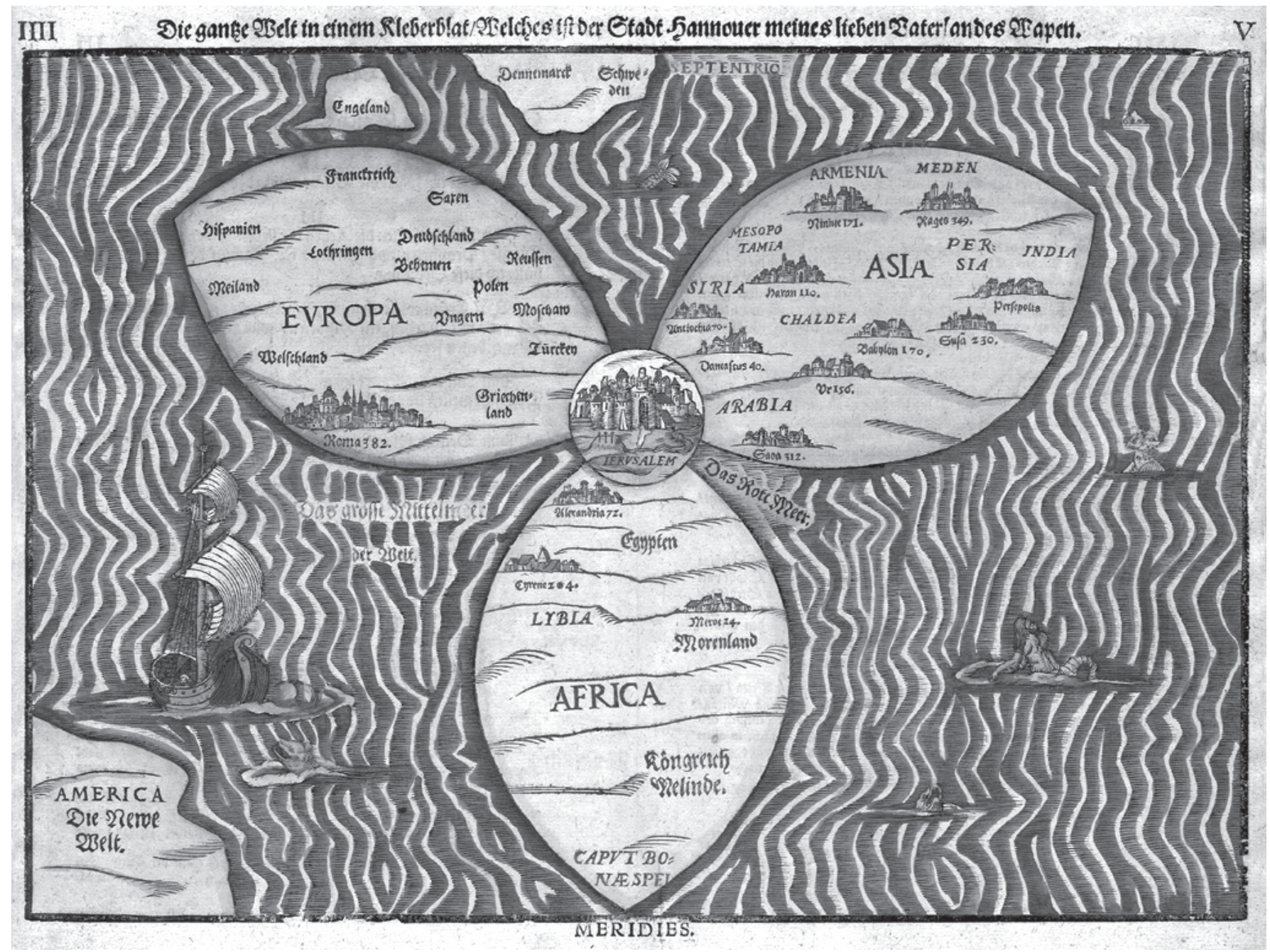




\title{
Forma, Gestão e Relações Sociais em Quadras Residenciais Cariocas
}

\section{Ana Paula Garcia de Medeiros*}

\begin{abstract}
Resumo: Este trabalho procura entender as relações entre forma, uso e interações sociais desenvolvidas entre moradores de quadras residenciais com pátio central, do ponto de vista dos usuários, a partir do estudo de dois exemplos na cidade do Rio de Janeiro: a quadra conhecida como Selva de Pedra no Leblon e a outra no limite entre os bairros da Urca e Botafogo. A pesquisa sugere que a forma, a gestão e a rede de relações sociais que se estabelecem entre os diversos usuários e entre esses e o espaço agem sobre essa apropriação desses espaços pelos usuários. Os resultados apontam para a importância do projeto arquitetônico em sua dimensão formal, bem como para a necessidade de investimento em formação de novos gestores locais, por ser esta uma dimensão fundamental para a criação e o fortalecimento dos laços sociais que sustentam a vida pública nestes espaços da cidade.
\end{abstract}

Palavras-chave: Espaço; território; relação forma e uso.

\begin{abstract}
The article aims to understand the relations between form, use and social interactions in residential blocks with inner courtyards, considering user's perception. It reports the conclusions of a study carried out in two blocks of Rio de Janeiro city: one of them known as Selva de Pedra, Leblon, and the other located between Urca and Botafogo districts. The research assumes that form, management, and the network of social relations established amongst the various users and between these users and space itself act upon appropriation of a territory. The ultimate results point out to the importance of the architectural project in conceiving spaces concerned with those aspects, as well as with the formation of new local managers, since management comprises a fundamental perspective to the creation and strengthening of the social bonds that sustain public life in these urban spaces.
\end{abstract}

Keywords: Space; territory; relation form; use and social interaction.

A pesquisa que originou este artigo investiga espaços livres públicos e as relações entre forma e uso neles existentes. Uma observação atenta verifica que alguns espaços, por mais bem projetados, segundo cânones de design e programas bem estudados e aplicados, podem não produzir nenhum sentido. Assim, pessoas que

\footnotetext{
* Relações Públicas. Graduada na Universidade do Estado do Rio de Janeiro. Arquiteta e urbanista graduada pela Universidade Federal do Rio de Janeiro. Mestre em Urbanismo pela Universidade Federal do Rio de Janeiro. Professora de Planejamento Urbano no curso de Gestão de Negócios da Universidade Veiga de Almeida. Endereço postal: Av. General Felicíssimo Cardoso, 500, Barra da Tijuca, Rio de Janeiro. Endereço eletrônico: anapaulagm @gmail.com.
} 
poderiam usar esses espaços, seja porque moram perto, seja porque passam por ali a caminho de trabalho, não o fazem, e esses espaços vivem vazios, sem movimento, acabando, muitas vezes, por se cristalizar no imaginário das pessoas como um lugar perigoso ou degradado.

Por outro lado, há outros espaços que despertam um sentimento de identidade, um vínculo muito forte entre indivíduos. Esses lugares têm vida, estão sempre ocupados, com uma variedade de gente e atividades que frequentemente extrapola o programa imaginado no projeto do espaço. Há espaços, inclusive que nem sequer foram projetados, mas surgiram espontaneamente, por meio da sobra de terrenos de urbanização, ou da demolição de edificações, ou outros mecanismos, e que são apropriados pela população, que os preenche de usos e significados. Alguns espaços podem até não estar cheios de gente o tempo todo, mas têm uma força simbólica tal que mobiliza a comunidade ao redor. São espaços que costumam estar mais bem cuidados e se tornam referência muito facilmente.

Nesse sentido, foram avaliadas, por meio de dois estudos de caso, as relações entre forma e uso, procurando analisar a vitalidade de certos espaços públicos e os elementos de projeto que favorecem essa atribuição de sentido e identidade. Os estudos mais recentes sobre esse tema apontam outras questões, além do projeto, que devem ser consideradas ao se tentar compreender o uso e o significado dos variados espaços na cidade.

Os espaços públicos na cidade são espaços políticos por excelência. Neles se realizam trocas sociais importantes, e, por estarem submetidos ao olhar de todos, aí se revelam conflitos e se ensaiam soluções de convivência. No entanto, observase atualmente uma tendência cada vez mais frequente da primazia do privado e individual sobre o público e coletivo, conforme já indicou Santos:

A ausência de diversidade e a busca de transparência, são eles mesmos elementos de um sistema de valores. Formam um paradigma da vida urbana que enfatiza o indivíduo, sua privacidade e sua autonomia com relação aos outros... daí de-correndo a abdicação da responsabilidade coletiva, a falta de vida pública (SANTOS, 1981, p. 132).

Os dois exemplos aqui apresentados, ambos espaços públicos na cidade do Rio de Janeiro, são: o Parque General Leandro, localizado numa área de limite entre a Urca e Botafogo, e a Praça Milton Campos, situada no interior do conjunto residencial conhecido como Selva de Pedra, no Leblon. Em ambos os casos, analisaram-se, sob o enfoque formal, social e cultural, as especificidades, as relações sociais ali construídas e as dinâmicas de usos, conflitos e apropriação existentes. Nos dois casos, tratam-se de quadras residenciais que contêm um pátio central, que se apresenta como espaço livre público de lazer.

A suposição inicial era de que a morfologia dessas quadras, em forma de pátio central, favorecia a percepção da área como espaço privativo daquela comunidade por parte da maioria dos não-moradores e, portanto, essa forma desempenhava um forte papel na construção da imagem e dos usos destes pátios. O fato 
\} Forma, Gestão e Relações Sociais em Quadras Residenciais Cariocas - MEDEIROS, A. P. G. M. \}

de o pátio estar confinado, ter pouca visibilidade para quem está externo à quadra, e ter sido concebido prioritariamente para o lazer dos moradores, seria então o motivo principal para explicar suas formas de utilização e apropriação.

Porém, logo se percebeu que o desenho, exclusivamente, não esgotava a análise. Pelo contrário, apenas abria a porta para um universo de outras indagações e palpites. Há sempre a questão do cenário sociocultural. Afinal, são os lugares, tomados em seu conjunto, que importam e não projetos simplesmente. De acordo com Whyte, "para realmente funcionar como lugares de coesão, espaços públicos têm que ser projetados com pessoas e usos em mente" (WHYTE, 1980, p. 5). Dito de outra forma, isso quer dizer que um dado espaço na cidade, por si só, tomado apenas em sua dimensão física, de forma e desenho, não é nada. "São as pessoas que dão utilidade aos espaços, emprestam-lhes valor, e fazem deles um sucesso, ou então não os usam e os condenam ao fracasso" (JACOBS, 2001, p. 97).

Assim sendo, novas questões foram incorporadas à pesquisa: quem são as pessoas que aí vivem? Como usam efetivamente o espaço para elas projetado? Além delas, que outras pessoas usam também este espaço? Que relações são aí estabelecidas entre estes usuários? E entre eles e o espaço que partilham? Uma nova hipótese, portanto, juntava-se à primeira e, segundo essa nova hipótese, esses grupos sociais, com seus valores culturais e suas interrelações, também contribuiriam para entender o funcionamento dos espaços estudados.

Por fim, um terceiro fator se revelou fundamental para a pesquisa: o elemento gestão. É interessante notar que esta é uma dimensão ainda pouco avaliada nos estudos que envolvem as análises de forma e uso. Alguns autores, como Lynch e Zeisel, tangenciam o tema, mas não se aprofundam nele. Hertzberger, por sua vez, não só associa o uso do espaço à gestão, como dá a este conceito a definição que adotamos aqui, quando diz que "o caráter de cada área dependerá em grande parte de quem determina o guarnecimento e o ordenamento do espaço, de quem está encarregado, de quem zela e de quem é ou se sente responsável por ele" (HERTZBERGER, 1999, p. 22).

Assim, concluiu-se que existem três fatores que se conjugam para dar vitalidade e conformação aos espaços livres públicos aqui enfocados: a forma, as relações socioculturais aí estabelecidas e a maneira como ele é gerido. A pesquisa, em seus resultados mais amplos, procurou demonstrar como esses fatores se imbricam e como influenciam uns aos outros. Neste artigo, procuramos dar ênfase aos aspectos que descrevem a constituição desses espaços como territórios e as relações sociais que neles se estabelecem.

Nesse ponto, é importante explicitar o arcabouço metodológico que orientou a pesquisa. Segundo Lefebvre, a compreensão de um fenômeno urbano depende, primeiramente, de métodos descritivos, eles próprios variados. Ele menciona a descrição das áreas habitadas, unidades de vizinhança, formas de relações; a descrição fenomenológica, que se ocupa dos laços entre as pessoas e os lugares; e a descrição empírica, que enfatiza a morfologia, procurando dar conta do que veem e fazem as pessoas num contexto urbano (LEFEBVRE, 1999, p. 51). Corroborando nossa opção, portanto, por um método descritivo, recorremos a Zeisel, que acrescenta que estudos descritivos (ou diagnósticos, como ele também os chama) ajudam a aprofundar a compreensão de uma situação: mais do que "salvaguardas rigorosos da confiabili- 
dade e especificidade das descobertas"; eles dão um panorama sobre a estrutura e dinâmica de uma situação global, identificando seus propósitos, suas partes e as relações entre elas (ZEISEL, 1984, p. 60).

A análise crítica dos dados levantados a partir daí se apoiou também num método comparativo, a partir de estudos de caso. Ainda de acordo com Zeisel, estudos de caso são usados para "descrever e diagnosticar objetos singulares e inter-namente complexos: indivíduos, edifícios, episódios, instituições, processos, sociedades" (ZEISEL, 1984, p. 60). Foram então analisados criticamente os dados levantados nos dois espaços estudados, na tentativa de compreender suas semelhanças e diferenças em cada um dos vieses estudados: morfológicos, socioculturais e gerenciais.

Com esse quadro teórico-metodológico em mente, uma primeira etapa da pesquisa foi documental, realizada em bibliotecas e arquivos, com o intuito de recolher dados históricos que permitissem compreender o processo de formação de cada uma das áreas de estudo. A pesquisa iconográfica paralela subsidiou a investigação geral com a coleta de imagens, plantas cadastrais e projetos das referidas áreas, bem como fotografias atuais e antigas, ilustrando tanto o processo de evolução morfológica quanto as formas de apropriação desses espaços.

Para a compreensão dos aspectos formais, sociais, de percepção, dos usos e significados atribuídos ao local, foi usado o método da observação participativa, que procurou analisar tanto os traços físicos do espaço quanto os usos e comportamentos aí observados. Para isso, foram realizadas visitas regulares, em variados dias da semana e horários a cada uma das áreas. Além das anotações e das fotografias, foram utilizados também mapas ou diagramas, buscando dispor graficamente os principais fluxos existentes e a distribuição espacial das pessoas em suas atividades.

Foram realizadas também algumas entrevistas com personagens-chave para o entendimento do funcionamento das quadras: moradores, funcionários dos prédios, os presidentes das respectivas associações de moradores. As primeiras entrevistas realizadas tiveram um caráter exploratório, ajudando a suscitar questões e identificar pontos a serem explorados. Mais adiante, outras entrevistas contribuíram para cotejar dados e informações e aprofundar temas que foram surgindo ao longo da pesquisa.

Por fim, foram aplicados questionários estruturados, com o intuito de subsidiar as observações de campo com dados fundamentados estatisticamente que ilustrassem as conclusões apontadas pela observação ou apontassem para aspectos ainda não percebidos ou inteiramente compreendidos. Contudo, esse instrumental funcionou mais do que técnica quantitativa, agregando qualidade ao estudo, por meio das inúmeras contribuições espontâneas dos respondentes, sob a forma de relatos e depoimentos escritos, que surgiram mesmo que não tenham sido expressamente solicitados.

Para evitar o perigo de vieses pessoais do pesquisador afetarem a amostra selecionada, foi utilizada uma amostra aleatória, a partir de uma moldura de amostragem, que é a lista de elementos a partir da qual é selecionada a amostra sistemática (BABBIE, 2003, p. 119). No nosso caso, isso correspondia à lista total de apartamentos de cada edifício em cada uma uma das quadras. A partir daí, cada $\mathrm{k}^{\circ} \mathrm{e}$ elemento na lista total, por exemplo, cada $5^{\circ}$ elemento, foi escolhido para inclusão na amostra. Os questionários eram do tipo autoadministrados, distribuídos nas caixas de correio dos edifícios, acompanhados de uma carta de apresentação, e foram recolhidos na 
portaria uma semana depois. Cerca de 10\% dos questionários entregues foram devolvidos preenchidos, o que foi considerado um resultado satisfatório.

\section{Caracterização dos Objetos de Estudo}

A primeira área que estudamos foi o Parque General Leandro. Esta área se localiza no centro da quadra delimitada pelas ruas Lauro Müller e Ramon Castilla, no limite entre Botafogo e Urca, e está encravada numa área residencial existente em meio a características geográficas peculiares e um consolidado uso institucional e comercial, representado pelas presenças marcantes do shopping Rio Sul, numa ponta, e pelo campus da Universidade Federal do Rio de Janeiro na outra. São dezoito edifícios, numa área total de aproximadamente $36.000 \mathrm{~m}^{2}$, que integram um projeto de loteamento aprovado em 1945, mas que teve o auge de sua implementação a partir de fins da década de 1960.

Dadas as características topográficas (a área da praça está acima do nível da rua Lauro Müller, cerca de três metros) e a própria conformação dos edifícios que o envolvem, o caráter público do parque assume uma certa ambiguidade, podendo parecer, aos olhos dos não-conhecedores da área, como espaço de uso privativo dos prédios residenciais. Esta "confusão" é, de certa forma, prezada pelos moradores locais, que identificam na localização pouco visível da área, na ausência de tráfego de automóveis (restrito ao acesso às garagens) e no fato de os edifícios todos terem suas janelas voltadas para a praça, um certo valor de "resguardo", caracterizado pelo uso de termos como "tranquilo", "sossegado" ou "protegido", na descrição do local por residentes.

Supunha-se, inicialmente, que os moradores valorizassem também a oportunidade de maior controle sobre os eventos aí ocorridos e consequentemente maior segurança. Esta hipótese, entretanto, não se comprovou ao longo da pesquisa, e o sossego ou tranquilidade associados à praça foram creditados mais imediatamente à ausência de trânsito intenso de outros usuários, ou seja, à constatação de que aí impera um ritmo mais doméstico e menos urbano, se se pode chamar assim, por comparação a outras praças mais expostas aos ritmos frenéticos da cidade.

Os únicos outros usuários que partilham costumeiramente deste espaço são outros moradores de comunidades muito próximas, como os da vila residencial da rua Xavier Sigaud e os da favela Vila Benjamin Constant, localizada atrás do Instituto de mesmo nome, além dos transeuntes mais ou menos frequentes, que utilizam o parque como passagem entre a Universidade Federal do Rio de Janeiro, cujo campus da Praia Vermelha se encontra em uma das pontas do conjunto, e o Rio Sul, com sua concentração de pontos de ônibus em frente, localizado na ponta oposta.

A segunda área é a Praça Milton Campos, inserida no conjunto da Selva de Pedra, no Leblon. Esta quadra residencial surgiu a partir do loteamento da área resultante da remoção da favela da Praia do Pinto, ocorrida no final dos anos 1960, segundo uma prática de urbanização então bastante usual. Numa área de cerca de 92.000 m²$^{2}$, delimitada pela Av. Afrânio de Mello Franco e pelas ruas Gilberto Cardoso, Fadel Fadel e Humberto de Campos, foram construídos quarenta prédios, com um interior de quadra igualmente destinado à construção de uma praça, cuja finalidade primordial era o lazer dos moradores. 
À semelhança do projeto construído para a rua Lauro Müller, esta praça central foi desenhada como um espaço rigorosamente público, embora ambiguamente percebida pelos transeuntes e não-frequentadores da área como um espaço "semi-privado". Essa percepção se deve principalmente à pouca visibilidade que se tem da praça, agravada pelo fato de que o loteamento constitui quadrilátero com dois anéis de edifícios, dispostos alternadamente, o que praticamente impede que o transeunte se dê conta da existência da praça interna. Um pequeno vislumbre é possível da entrada das ruas de acesso, mas o fato de elas serem guardadas por cancelas de controle (que apenas inibem o estacionamento dos carros nos pequenos pátios de estacionamento internos, mas não interferem no fluxo de pedestres) reforça ainda mais esta percepção do espaço público como privado.

Da mesma maneira que na quadra de Botafogo, aqui também se identifica um uso institucional e comercial bastante forte no entorno imediato do conjunto, exemplificado pelos clubes Paissandu, Flamengo, Monte Líbano e Associação Atlética do Banco do Brasil, bem como pelo mercado da Cobal.

O loteamento da Selva de Pedra é composto por quarenta edifícios de uso exclusivamente residencial, conforme determinado em seu projeto, o que restringe a diversidade de usos e fluxos que normalmente se encontra em áreas de uso misto. Apesar disso, como há muito comércio, clubes e escolas em torno, verifica-se um intenso trânsito de pessoas que cruzam a praça diagonalmente, indo e vindo das várias atividades que florescem ali ao redor. A maior parte desses transeuntes é de moradores do próprio conjunto, porém os moradores da Cruzada São Sebastião, vizinha do conjunto, também usam a praça como atalho, bem como outros frequentadores que conhecem o local por trabalhar próximo, ou por indicação de terceiros. Os principais destinos deste trânsito são a Cobal, as escolas próximas e os pontos finais de várias linhas de ônibus, localizados na Av. Afrânio de Melo Franco, ao longo do muro do Clube Paissandu.

Os dois projetos de loteamento apresentam, portanto, algumas semelhanças imediatas, a partir de observação preliminar, tais como semelhanças de desenho e usos ou programas. Ambos são loteamentos residenciais, de edificações multifamiliares voltadas ao atendimento da classe média, e ocupam uma quadra cujo centro foi resguardado para a existência de uma praça pública, que atendesse a um programa fundamentalmente voltado ao lazer dos moradores adjacentes. Entretanto, enquanto o loteamento da rua Lauro Müller é originalmente um projeto da década de 1940, na esteira das propostas elaboradas para a Urca pelo engenheiro e professor José Octacílio de Saboya Ribeiro, posteriormente retomado e executado praticamente sem modi-ficações, o projeto de loteamento que deu origem à Selva de Pedra data de fins dos anos 1960 e é fruto de um pensamento urbanístico que envolvia a remoção de favelas (reassentadas em outros conjuntos residenciais construídos na periferia da cidade) como parte de um processo de urbanização e solução dos problemas urbanos. A autoria do projeto, com tintas modernistas, é do arquiteto Marcos Konder Netto.

Com relação às questões inicialmente levantadas nesta pesquisa, sobre a existência ou não de elementos de projeto que favoreçam a atribuição de sentido e identidade aos espaços, Kevin Lynch propõe uma resposta. Segundo ele: 
(...) deve haver variedade e plasticidade no projeto desses espaços. Mas a escolha deve estar ao alcance - o que coloca a questão do ACESSO, tomado tanto em sua dimensão de conexão psicológica quanto física. Os espaços devem estar fisicamente próximos de seus usuários. Uma rede de pequenos espaços espaIhados pela cidade funciona melhor que um grande espaço fora da cidade.

Políticas públicas devem privilegiar os grupos mais carentes dessa possibilidade de escolha. Os espaços livres públicos servem como locus, por excelência, para contatos sociais novos, inesperados, e livres de muitas das restrições da rotina diária. Se nós valorizamos a mobilidade social e nos perturbamos com a segregação, devemos ter por política localizar espaços livres ativamente utilizados entre ou igualmente acessíveis a diferentes grupos sociais, promovendo a APROXIMAÇÃO que for possível entre eles. ${ }^{1}(\mathrm{LYNCH}, 1990$, p. 61).

Lynch diz ainda que há determinadas dimensões de análise e vivência da cidade que se devem prioritariamente às suas características espaciais. Essas dimensões seriam atributos formais da cidade, e ele propõe a existência de cinco dimensões básicas, das quais duas são fundamentais para a compreensão da perspectiva social e cultural que adotamos no estudo das duas quadras em questão, e uma terceira aponta, ainda que não se aprofunde, para o tema da gestão, que também procuramos enfocar.

Estes cinco atributos são: a vitalidade (grau em que a forma suporta as funções vitais da população ali residente e protege a sobrevivência da espécie), o acesso (capacidade do aglomerado de alcançar outras pessoas, atividades, recursos, serviços, informações ou locais, incluindo a quantidade e diversidade de elementos que podem ser alcançados), o sentido (clareza com que o aglomerado pode ser apreendido e mentalmente diferenciado e estruturado no espaço e no tempo por seus residentes), a adequação (grau em que a forma e a capacidade dos espaços e equipamentos correspondem ao padrão e à quantidade de ações em que as pessoas normalmente se envolvem ou desejam se envolver) e o controle (grau em que a utilização e o acesso a espaços e atividades, sua criação, reparação, modificação e gestão são controlados por aqueles que os usam e neles trabalham ou residem) ( $\mathrm{LYNCH}$, s/data, p. 117).

As dimensões fundamentais para o estudo das quadras abordadas seriam o acesso, a adequação e o controle. Nesse momento, fazendo ressonância a algumas outras indagações de Lynch, perguntamo-nos: em que grau os usuários e habitantes reais dessas quadras as controlam efetivamente? Quais as vantagens de se buscar esse controle coletivo? O termo controle assume, nesse caso, uma conotação policialesca e restritiva. Assim, preferimos adotar a noção da gestão, que lida com questões como a responsabilidade pelo ordenamento do espaço, por sua conservação e bom funcionamento.

${ }^{1}$ Grifos nossos. 
Reelaborando, então, quais as vantagens de se buscar esse gerenciamento coletivo do espaço? Segundo Lynch, melhora a adequação, já que as pessoas encarregadas são mais familiarizadas com o uso do local e, supostamente, mais motivadas para melhorá-lo. Por desdobramento, isso traria mais segurança, satisfação e liberdade. Porém, em face da realidade que desmente, tantas vezes, essa teoria, perguntase: será que esses usuários são competentes para exercer esse controle, ou, em nossos termos, essa gestão?

Em seu texto, Lynch aponta algumas maneiras usuais de se tentar minorar os conflitos espaciais: a primeira seria alargar o consenso social acerca dos direitos no espaço, para que as pessoas se adaptem às normas e ao poder estabelecido; a segunda seria a tolerância, ou seja, a busca de coexistência no espaço e no tempo, procurando manter a indiferença relativamente a ações estranhas dos vizinhos. Não funcionando essas instâncias, parte-se para a compartimentalização do espaço para evitar o confronto, ou então busca-se a intermediação da autoridade policial. Para Lynch, "o controle verdadeiramente cooperativo requer um dispêndio muito grande de energia nas comunicações e decisões do grupo, além de habilidade política. Seu preço é a educação, as discussões e a manutenção incansável da organização política" (LYNCH, s/data, p. 203).

A apropriação de um espaço público por residentes, como se fosse "privado", também fortalece a demarcação por parte do usuário desta área aos olhos dos outros, o que confere uma dimensão extra ao espaço público (HERTZBERGER, 1999, p. 17).

O problema, é bom que fique claro, não está na valorização do espaço privado, em si mesmo, mas que isso seja feito em detrimento do espaço público, isto é, que eles sejam colocados em confronto, como se a importância de um esvaziasse a importância do outro. Hertzberger acredita em que a oposição extrema entre público e privado, da mesma maneira que entre coletivo e individual é sintoma de uma desintegração das relações humanas mais básicas, expressada pela polarização entre a individualidade exagerada, com a supervalorização da dimensão privada do espaço, por um lado, e a coletividade exagerada, com a consideração hegemônica do espaço público, por outro.

\section{A Autopercepção dos Moradores}

Santos diz que "todo grupo social tem uma versão de si mesmo, uma imagem que cultiva e difunde" (SANTOS, 1981, p. 84). Nesse sentido, a categoria "vizinhos" costuma ser entendida "como uma comunidade moral, no seio da qual as pessoas reconhecem um conjunto de expectativas e obrigações mútuas" (SANTOS, 1981).

Durante a pesquisa, foram realizadas algumas entrevistas e aplicados questionários em ambas as quadras. Nos discursos analisados, pode-se perceber que a percepção que os moradores têm de si mesmos, como grupo social, acontece de maneiras diferentes na Lauro Müller e na Selva de Pedra. O morador da Lauro Müller se considera mais tradicional, gosta de pensar em sua vizinhança como uma grande comunidade. Alguns chegam a se referir ao lugar como "uma Zona Norte na Zona Sul", invocando um imaginário de subúrbio em que todos se conhecem e as relações sociais são próximas, informais, baseadas em camaradagem e no re-conhecimento de que todos partilham de uma mesma situação social, cultural e econômica. 
Na Selva de Pedra, um discurso aparentemente muito parecido encobre nuances diferentes. Não há tanta referência aos laços comunitários, embora os moradores também pensem em si mesmos como partilhando o mesmo nível de renda, o grau de instrução, os interesses, o acesso a determinadas instituições de ensino e lazer, ou mesmo o enquadramento em determinadas categorias profissionais. A identificação dessa homogeneidade serve para reforçar a distinção que eles fazem de si em relação à vizinhança.

Essa necessidade de se identificar em oposição a outrem vem da própria história de um conjunto que ocupa o lugar de uma favela. É a necessidade de se diferenciar dos que estavam ali antes. Essa diferenciação começa na maneira com que os outros (os moradores da Favela da Praia do Pinto) são referidos no próprio discurso oficial.

Os não-moradores também têm sua opinião a respeito da Selva de Pedra. Para Barbosa Lima, que descreve o Leblon em uma série de crônicas publicadas na internet, o bairro deixou há anos de ser um lugar prazeiroso e agradável, entre outros motivos, pela "ocupação da Selva de Pedra por forasteiros aspirantes à classe média". Para ele, os novos ocupantes, "felizes proprietários das novas unidades" erigidas sobre os "escombros fumegantes" da favela incendiada, manifestaram, desde o princípio, uma "xenofobia às avessas, corrupta e insolente, que se manifesta pela injustificada e imediata rejeição da cultura local e se consolida mediante a imposição de novos ícones e ídolos" (LIMA, 1999).

No extremo oposto desta ácida posição, está a defesa feita pelo autor do projeto que originou a Selva de Pedra. Para Marcos Konder Netto, a Selva de Pedra é "o oásis do Leblon", uma quadra diferente, na qual ele supõe que os moradores gostem muito de morar.

\section{As Relações Sociais Estabelecidas}

O uso cotidiano da praça é o mais potente instrumento de favorecimento à criação de uma rede de contatos sociais entre os moradores, tanto na Lauro Müller quanto na Selva de Pedra. Essas pessoas podem partilhar de uma mesma posição social e econômica, mas até para fortalecer esse conhecimento e essa identidadeS é preciso que elas conversem, convivam, estabeleçam relações. Em ambos os casos, a praça é o palco principal desse convívio, o elemento articulador da vida social desse grupo que se enxerga distinto de outros no que concerne à moradia. Por isso, a primeira condição de integração a essa rede é frequentar a praça.

Entre os usuários da praça, surgem, às vezes, tipos que se destacam e ganham alguma notoriedade na dimensão daquela comunidade, exercendo um papel importante na estrutura da rede social estabelecida. Whyte diz que o surgimento dessas figuras é mais frequente nos lugares mais bem utilizados e se refere a eles como "prefeitos" ou "gerentes" locais. Para Whyte, essas pessoas são "uma referência, ... funcionam como foco de comunicação e facilmente percebem qualquer alteração na rotina do lugar" (WHYTE, 1980, p. 64).

Um outro tipo de rede social também identificada nos dois casos é a rede filantrópica. Há um movimento estruturado e organizado de ação social, principalmente por meio do recolhimento de doações e participação em campanhas bene- 
ficentes. Segundo uma moradora da Selva de Pedra entrevistada para a pesquisa, as relações sociais estabelecidas por meio do convívio na praça é que permitem, em grande parte, que esse outro círculo de atividades exista. Ela diz:

Eu sei que a Selva de Pedra, por exemplo, tem uma boa rede de recolher doações...Tem o pessoal da Igreja dos Santos Anjos, e tem também o pessoal espírita, que faz a campanha do quilo. Um sábado por mês eles recolhem o que você quiser na sua casa, basta você avisar lá embaixo, ou deixar de véspera, desde um quilo de alguma coisa pra alguém, até livros, remédios que o prazo não esteja vencido, armação de óculos, qualquer coisa. É bacana, é legal (Entrevista).

A grande diferença entre as ações filantrópicas promovidas na Selva de Pedra e na Lauro Müller está no agente que as promove. Enquanto na Selva de Pedra essas atividades e campanhas são quase sempre mediadas por instituições religiosas locais ou do bairro, na Lauro Müller é a Associação de Moradores que as divulga, incentiva e às vezes até coordena, por meio de seus membros diretores. Isso não quer dizer que a comunidade não esteja no raio de ação de diversas instituições religiosas, como a Igreja de Santa Teresinha, localizada ao lado do shopping Rio Sul, e frequentada por grande parte dos católicos do conjunto. Mas a atuação da Associação de Moradores nessa esfera da vida da comunidade não deixa de ser algo a se notar.

\section{Os "Indesejáveis"}

Falamos das relações sociais que se estabelecem entre os iguais, co-habitantes da mesma quadra, e também sobre as relações que esses moradores estabelecem com grupos menos favorecidos, com os quais exercitam sua consciência social de classe média. Mas esses grupos, objeto de uma "benesse" ou caridade, não convivem cotidianamente com os moradores, não dividem o mesmo espaço. Como são, então, as relações com aqueles personagens que Whyte chama de "indesejáveis" (WHYTE, 1980, p. 60), os mendigos, pedintes, tipos esquisitos, vizinhos da favela, consumidores de drogas ou simplesmente estranhos que frequentam a mesma praça?

Há os estranhos que são identificados como membros da mesma classe social, embora não sejam pessoas conhecidas formalmente. Esses não são, em princípio, indesejáveis. E há os que são estranhos por serem identificados como diferentes, membros de outro grupo social, normalmente com menos status. Essa identificação é feita a partir de uma série de signos sociais, tais como vestimenta, linguagem, comportamento e pertencimento explícito a determinadas categorias profissionais.

Em 1981, Santos já havia percebido, na Selva de Pedra, que:

porteiros, faxineiros, peões de obra, empregadas domésticas, faxineiras, jornaleiros, biscateiros e ambulantes desenvolvem suas atividades ou fazem ponto no projeto. Pouco numerosos, são possíveis interlocutores no espaço público, mas as barreiras sociais são marcadas entre eles e os moradores por uma evitação 
mitigada. São todos estranhos, em maior ou menor grau, e suas relações com os habitantes da Selva de Pedra são funcionais, e por isso mesmo, apresentam uma poderosa tendência à formalidade impessoal (SANTOS, 1981, p. 115).

Por conta da literatura que relata os conflitos existentes entre os moradores da Selva de Pedra e os da Cruzada São Sebastião, a pesquisa resolveu investigar cuidadosamente como são hoje as relações entre os habitantes de cada uma das quadras e seus vizinhos próximos e mais pobres. No caso da Selva de Pedra, a Cruzada, e no caso da Lauro Müller, a Vila Benjamin Constant.

Na Selva de Pedra, as entrevistas com duas moradoras revelaram, num caso, certa indiferença, causada talvez pelo fato de a moradora não frequentar a praça; no outro caso, a constatação de que as relações se dão no âmbito da mediação da igreja:

Eu posso te dizer que até é bom. Porque, por exemplo, a gente conhece... eu conheço umas pessoas de lá por causa da igreja. Então quando elas passam aqui, é "oi, tudo bem?", "tudo bem, e tal...", "Ah, você esteve lá na igreja?" E eu sei que elas moram ali na Cruzada e elas sabem que eu moro aqui. Então, o relacionamento é bom (Entrevista).

O presidente da ADESPE (Associação de Moradores da Selva de Pedra) também faz questão de frisar que não há nenhum problema de relacionamento com os vizinhos: "eu vou lá, participo das festas que eles fazem, Festa de São João, e outras festas, sem o menor rancor. Se a gente puder ajudar sempre a gente ajuda" (Entrevista).

O próprio presidente da Associação de Moradores da Cruzada, a AMORABASE, reitera que:

o convívio com a Selva de Pedra é harmônico, morador de lá vem pra cá, a gente vai pra lá. Tem crianças aqui da comunidade que vão naquela pracinha, ficam lá brincando, não tem problema nenhum, jogam bola, andam de skate, então o convívio é bem harmônico (Entrevista).

Entretanto, o que foi observado é que há, de fato, um convívio, isto é, grupos que partilham o mesmo espaço simultaneamente, sem atritos. O que não há é interação. As mães das crianças da Cruzada não sentam junto com as mães das crianças da Selva de Pedra para trocar experiências, embora as crianças estejam no parquinho ao mesmo tempo. Na verdade, vários grupos se formam, consoante interesses ou características comuns. E isso acontece tanto numa praça quanto em outra. Há os grupos que vêm da Cruzada (ou da Vila), às vezes moradores, às vezes crianças e adolescentes que voltam da escola e param para uma brincadeira; grupos de funcionários dos estabelecimentos comerciais próximos, que se agregam em conversas 
na sombra, na hora do almoço; e diversos subgrupos de moradores, com variadas interseções: os que passeiam com cachorros, os que acompanham crianças pequenas, os idosos, os jovens.

Uma interação sistemática foi observada dentro desses subgrupos, e entre alguns deles, mas mais raramente entre grupos distintos de moradores e não-moradores.

As relações da Lauro Müller com os vizinhos da Vila são historicamente mais tranquilas e menos permeadas de conflitos. Também aí se observa a mão da Associação de Moradores, que estimula esse contato por meio de diversas atividades para as quais os moradores da Vila são convidados e estabelece parceria com a AMOVILA na realização de alguns eventos, como a Festa Junina e caminhadas ecológicas, entre outros. São ocasiões em que as pessoas têm a chance de conversar informalmente, estender suas redes de contatos e criar novos laços que desmistificam as diferenças. É claro que isso não acontece sempre, ou com todo mundo, mas as pequenas pontes que surgem já ajudam a criar um ambiente mais leve e coerente com o caráter público do espaço.

Outro elemento que favorece esta diluição de diferenças na Lauro Müller ainda que momentânea - é a quadra de esportes. Na hora do futebol é comum a formação de times mistos, moradores de toda a vizinhança, principalmente quando os jogadores são crianças.

A mesma condescendência não se verifica, entretanto, quando o assunto é o consumo de drogas. Nos dois conjuntos houve o relato de queixas quanto à existência de grupos de jovens que fumam maconha na praça. Na Selva de Pedra, essa foi uma das razões alegadas, na opinião de uma das moradoras, para o gradeamento dos lotes e instalação de guaritas e seguranças. Quando perguntada se, afinal, as pessoas que consumiam drogas na praça eram moradores ou gente de fora, ela admitiu que eram majoritariamente moradores, o que não impediria que houvesse também gente de fora, mas imagina que isso seja "coisa de adolescente". Confrontada, então, com o fato de que era inútil gradear se o "problema" era interno, a moradora se rendeu:

É. Claro, o problema não é tirar o sofá da sala, não é? Tirar a praça não vai adiantar nada. Mas, sem dúvida, a praça facilitava o ponto de encontro, e taí pra o que você quiser, desde tocar violão, até puxar um fumo, e se não tiver praça vai ser em outro lugar, não é um problema da praça (Entrevista).

Uma vez tratado como questão de segurança, o problema do consumo de drogas se desloca para a esfera de responsabilidade da polícia. Na Selva de Pedra, depois que se contrataram os vigias e se estabeleceu uma política de vigilância e controle não só para este, mas qualquer outro tipo de delito, a opinião dos moradores é de que as ocorrências dessa natureza diminuíram bastante. Já na Lauro Müller, o assunto segue figurando entre os principais problemas da comunidade.

A outra categoria de indesejáveis que se observou existir é a de mendigos, moradores de rua e pedintes em geral. Na Selva de Pedra, alguns moradores re- 
lataram que não se dão conta da presença de mendigos na praça, e acreditam que eles não existam por ali. Provavelmente, como lembrou uma das entrevistadas, há algum tipo de repressão à permanência de mendigos no local. Apesar disso, no questionário, alguns moradores se queixaram, dizendo se sentirem incomodados e até ameaçados com a presença dessas pessoas na praça.

Na Lauro Müller, o tema rende, de tempos em tempos, uma movimentação. Há um contingente mais ou menos regular de meninos de rua que se abrigam pelas redondezas. Alguns são engraxates, alimentam-se da caridade dos donos e frequentadores de padaria e botequins próximos, algumas vezes até jogam bola com as outras crianças na quadra. Sua presença é testemunha do abismo social que cinde nossa sociedade e, na falta de uma solução mais definitiva para a questão, algumas pessoas prefeririam pelo menos afastá-los de suas vistas e de seu constrangimento.

Quando trata do assunto, estritamente do ponto de vista do desenho de espaços urbanos que funcionem ou não, que atraiam ou afastem as pessoas, Whyte lembra que "espaços projetados para manter afastados os indesejáveis - ladrões, mendigos, hippies - por exemplo, tendem a afastar outras pessoas também. Ao contrário, lugares que atraem pessoas tendem a ser relativamente livres de problemas" (WHYTE, 1980, p. 7). E ele arremata comentando que muitos executivos e planejadores têm um medo quase obsessivo de que, se um lugar for atraente para as pessoas em geral, poderá atrair também pessoas indesejáveis. Na opinião de Whyte, "lugares projetados com desconfiança têm exatamente o que se espera deles e são, ironicamente, os mais prováveis lugares onde encontrar exatamente o que se queria evitar" (WHYTE, 1980, p. 60).

\section{A Questão dos Territórios}

O conceito de território com que trabalhamos é originado na Geografia, e enfatiza o caráter político do território. Nesta perspectiva, o espaço geográfico é o substrato, o palco, pré-existente ao território. Para Claude Raffestin, "o território se forma a partir do espaço, é o resultado de uma ação conduzida por um ator sintagmático (ator que realiza um programa) em qualquer nível. Ao se apropriar de um espaço, concreta ou abstratamente [...] o ator 'territorializa' o espaço". (RAFFESTIN, 1993, p. 143).

A abordagem de Marcelo Lopes de Souza sobre o território é política e também cultural, visto que este autor identifica, nas grandes metrópoles, grupos sociais que estabelecem relações de poder formando territórios no conflito pelas diferenças culturais. Souza salienta que o território é um espaço definido e delimitado por e a partir de relações de poder e que o poder não se restringe ao Estado e não se confunde com violência e dominação. Assim, o conceito de território deve abarcar mais que o território do Estado-nação. Nas palavras do autor, "todo espaço definido e delimitado por e a partir de relações de poder é um território, do quarteirão aterrorizado por uma gangue de jovens até o bloco constituído pelos países membros da OTAN" (SOUZA, 2001, p. 11).

No caso das praças em questão, a demarcação de territórios, onde se verifica a prioridade ou hegemonia de uso deste ou daquele grupo, é principalmente uma 
função do desenho. No caso da Lauro Müller, a forma alongada, em "L", bem como a disposição do mobiliário, ajudam a conformar espaços dedicados, em princípio, a determinadas atividades. Assim, temos os aparelhos de ginástica, no centro da área de saibro, frequentados por jovens rapazes e alguns senhores; os brinquedos onde se divertem as crianças pequenas, acompanhadas de perto por suas mães ou babás; as mesas de jogos ocupadas por aposentados; e a quadra de esportes.

Em várias áreas da praça, a sensação de territorialidade se reveza no tempo e o mesmo espaço pode ser território de um ou de outro grupo, que se sucedem conforme a hora do dia. Na Selva de Pedra isso é bastante frequente, já que a forma octogonal e a pequena dimensão do pátio (em comparação com o da Lauro Müller) não favorecem muito a configuração espacial de territórios.

Mesmo assim, alguns setores podem ser majoritariamente ocupados por alguns grupos em certos momentos. É o caso dos bancos próximos à cabine da PM, que ficam cheios de idosos de manhã, o que é facilmente percebido pelos próprios moradores. Além disso, evidentemente, o uso consagra o território. O melhor exemplo é a área usada pelos meninos da Selva de Pedra para o futebol, já que o pátio não dispõe de quadra específica para isso. Nas palavras de uma moradora:

Depois também tem o seguinte, aquela coisa ali que seria a grande avenida da pracinha, é o lugar do futebol. Toda vez que rola o futebol, você vê os bancos cheios de meninos, de todas as idades, desde garoto pequeno até rapaz feito, tudo parado ali assistindo, ou esperando pra entrar... (Entrevista).

É importante retomar aqui a ideia de gestão, que implica mais do que uma abordagem meramente administrativa. Analisar a gestão, em nosso caso, significa investigar em que grau a comunidade se sente responsável pelo lugar em que vive e quais as maneiras que encontra para se organizar de modo a melhor zelar por seus interesses no que diz respeito a esse ambiente: como se relaciona com as instituições encarregadas da conservação e manutenção dos espaços físicos, como lida com as questões de segurança e controle e como administra os conflitos que inevitavelmente surgem na condução das ações decididas.

Um dos aspectos que conferem o caráter público ao espaço, conforme a conceituação de Hertzberger vista anteriormente, é a questão da responsabilidade sobre sua manutenção e conservação. Nas quadras estudadas, esta responsabilidade, em princípio, é do poder público e suas concessionárias. Mas diferem as formas com que as respectivas comunidades, por meio de suas associações de moradores, gerenciam o assunto.

Há uma série de verificações e providências a serem tomadas continuamente para o bom funcionamento das praças, considerando-se aqui sua dimensão física: poda de árvores, plantio e manutenção de canteiros, reparos em pisos, equipamentos, grades, brinquedos, bancos, troca de lâmpadas queimadas, retirada de entulhos, consertos em vazamentos de água e esgoto na rede pública, entre outros. Essas funções são de competência de órgãos diversos, às vezes da esfera municipal, outras da esfera estadual. Os moradores esperam que suas respectivas Associações de 
\} Forma, Gestão e Relações Sociais em Quadras Residenciais Cariocas - MEDEIROS, A. P. G. M. \}

Moradores zelem para que todas essas coisas funcionem devidamente e, quando algo não está em ordem, que elas acionem o órgão responsável e garantam, de certa forma, a execução do serviço.

Em cada uma dessas praças, essas tarefas são conduzidas de maneira distinta. Na Lauro Müller, a ALMA (Associação dos Moradores da Lauro Müller e Adjacências) adotou a manutenção dos canteiros e gramados do Parque General Leandro, das ruas Lauro Müller, Ramon Castilla e Xavier Sigaud, por meio da assinatura de um termo de adoção junto à Fundação Parques e Jardins, de forma que é a própria associação de moradores que faz a manutenção dos canteiros, apara os gramados e faz as pequenas podas.

Na Selva de Pedra, por outro lado, a manutenção e conservação da praça é função de uma política regular da prefeitura e seus órgãos, cabendo à ADESPE, principalmente, informar às instâncias responsáveis quando da necessidade de se efetuar algum conserto ou solicitar alguma melhoria.

\section{Conclusão}

No estudo destas duas quadras tão peculiares e pouco comuns na paisagem urbana do Rio de Janeiro, foram analisados três aspectos que, entrelaçados, ajudariam a responder à pergunta incial: como funcionam essas quadras? Como são percebidas e usadas? E por quê? Estes aspectos foram a forma, as relações sociais estabelecidas no espaço, que determinariam os usos observados, e a gestão.

O primeiro aspecto analisado foi a forma. Não apenas o desenho em si, a aparência ou estrutura física, mas a forma sob o conceito mais abrangente adotado por Lynch, que engloba as pessoas, suas atividades e fluxos, que, em conjunto, configuram o espaço. O desenho desses pátios, conformados por um anel de edifícios residenciais e isolados do trânsito de automóveis, enseja um uso cotidiano muito parecido. O dia a dia dessas quadras é semelhante, com as crianças e velhinhos de manhã, os adolescentes que vão e voltam da escola, os jovens que se reúnem à noite, a circulação de moradores e vizinhos que cortam caminho em direção ao comércio que existe ao redor.

A pesquisa verificou que o vínculo dos moradores da Selva de Pedra com sua praça é um pouco menos estreito do que o verificado na Lauro Müller, e crivado, por sua vez, de ambivalências que se reportam à história de sua constituição, como conjunto que veio a ser construído em área antes ocupada por favela. Isto influenciou a maneira como esses moradores construíram a imagem que têm de si mesmos (principalmente porque a maioria é de moradores antigos, que aí se estabeleceram desde o início, há cerca de trinte anos), e a maneira como se relacionam tanto com este espaço como com seus vizinhos imediatos, da Cruzada São Sebastião, alguns dos quais eram moradores da mesma favela que foi daí removida.

Esta situação explica, em parte, as contradições de discurso encontradas, em que ora se revelam laços afetivos semelhantes aos encontrados na comunidade da Lauro Müllers e ora se percebem indiferenças e até mesmo ressentimentos velados. Mesmo assim, os termos "tranquilo", "sossegado" ou "protegido" também foram muito usados na descrição do local, com o mesmo sentido de "resguardado do movimento mais intenso do restante da cidade". 
Na Lauro Müller, a forma favorece a dispersão. A praça mais alongada permite a criação de muitos territórios, nichos que privilegiam usos distintos ao longo o dia. A existência de pontos de comércio no pavimento térreo de alguns dos edifícios também contribui para um fluxo mais intenso e variado de pessoas, sugerindo um caráter mais público a esse espaço.

As praças estudadas são públicas, mas, como estão confinadas no interior das quadras e, a rigor, nem a visibilidade - e por conseguinte - nem o acesso a elas é totalmente franqueado, pode-se dizer que são espaços factíveis de serem percebidos como privados. Isso fortalece a demarcação por parte do usuário desta área aos olhos dos outros. Os moradores, por se darem conta de que são largamente majoritários entre os frequentadores, rapidamente identificam os "de fora", e alguns chegam a senti-los como intrusos. Ou se apropriam do espaço a ponto de se sentirem com mais direitos sobre ele do que os outros.

Além do desenho em si, outros elementos formais também contribuem para o entendimento de como as praças são usadas. A existência de um programa adequado e a disposição de um mobiliário condizente com esse programa, por exemplo, é um desses fatores.

A forma, então, é um elemento preponderante, embora não tenha autonomia. Ela não responde sozinha pelo estabelecimento de relações sociais, de nenhum tipo ou qualidade, mas pode colaborar para o estreitamento dessas relações ou literalmente dar as costas a elas. O fato de que alguns lugares encorajam as trocas sociais está no princípio do argumento de Whyte, por exemplo, de que são justamente esses lugares que funcionam melhor e exatamente por esse motivo.

Mas não é só a forma que conta. O fato de esses loteamentos terem sido ocupados majoritariamente por um determinado grupo social, que, por motivos vários - sociais, culturais, econômicos -, acabou permanecendo no local por tantos anos, sem a rotatividade que caracteriza muitos outros assentamentos, também colaborou no estabelecimento dessas relações. Famílias que se conhecem há anos, gerações que se sucedem no mesmo apartamento, ou migram para o edifício do lado, são fenômenos comuns de se encontrar nos dois casos.

Mas a grande diferença desses lugares, juntamente com a forma, está na gestão, fator que se mostrou fundamental para a compreensão das relações entre forma e uso. É o elemento que potencializa o uso e promove o estreitamento dos vínculos, fortalecendo o sentido de comunidade. A gestão, nesse caso, pressupõe uma ação coletiva de zelo e responsabilidade pelo lugar onde se vive. Teoricamente, a expressão desse zelo pode se manifestar de várias formas, das mais espontâneas e informais, às mais organizadas e institucionais. Usar o espaço de forma a conserválo, não depredando suas instalações e elementos, é uma forma de se manifestar responsável por ele. Interferir educativamente quando se presencia um ato de vandalismo é outra. Decidir, em conjunto, delegar essas ou outras tarefas a terceiros e supervisionar sua atuação, também. Ou seja, nesta concepção, a gestão está diretamente ligada à cidadania, que, segundo Ferreira dos Santos, "(...) é a convicção da autopertinência a um universo social que compartilha um conjunto de representações e relações sociais. A cidadania, mais que um estatuto formal, é o exercício da responsabilidade com relação ao que é comum" (SANTOS, 1981, p. 130). 
Outras maneiras de gerir o espaço e a vida pública, certamente haverá. Essas duas comunidades optaram por constituir Associações de Moradores para as representar e cuidar de seus interesses, nesse aspecto. E, segundo Lynch, "as pessoas que controlam um local devem ter os motivos, as informações e o poder para o fazerem bem, um compromisso com o local e com as outras pessoas e criaturas que aí habitam, uma disposição para aceitar o fracasso e corrigí-lo" (LYNCH, 1981, p. 200).

Todavia, o que pudemos observar foram realidades nem sempre consoantes com esses ideais. Aparentemente, a Associação de Moradores da Lauro Müller cumpre seu papel, a despeito da tensão contínua para acomodar as dissenções internas, o que não só é comum como enriquecedor para o processo de gestão como um todo. Na Selva de Pedra, porém, verificou-se um significativo descontentamento da população a esse respeito. Durante o período de observação e entrevistas, o panorama contemplado foi realmente de pouca participação da Associação na vida da comunidade. Como está, a associação é mais um braço normativo do poder público dentro da comunidade do que voz da comunidade junto a ele. Ela intermedeia a atuação da administração municipal na área e o faz competentemente, zelando principalmente pela ordem e segurança do conjunto, mas falha no diálogo com os moradores, esvaziando seu papel na comunidade e tornando-se alvo, no mais das vezes, de demandas burocráticas.

A pouca alternância na cúpula dessas entidades também sugere uma baixa disposição para a vida política e comprometimento com a coletividade, por parte desses moradores, o que, por outro lado, dificulta ainda mais a atuação das associações. Não cabe aqui discutir os motivos para esse pouco engajamento, mas é importante sublinhar que a formação de novos gestores sociais é uma tarefa social das mais úteis e urgentes. 


\section{Referências Bibliográficas:}

BABBIE, Earl. Métodos de pesquisa de survey. Belo Horizonte: UFMG, 2003. BORDO, Adilson Aparecido et al. As diferentes abordagens do conceito de território. São Paulo, 2004. Disponível em . Acesso em 30 de julho. 2009. CARR, S.; FRANCIS, M.; RIVLIN, L. e STONE, A. Public space. Cambridge: Cambridge University Press, 1992.

HERTZBERGER, Herman. Lições de Arquitetura. São Paulo: Ed. Martins Fontes, 1999. JACOBS, Jane. Morte e vida de grandes cidades. São Paulo: Ed. Martins Fontes, 2001. LEFEBVRE, Henri. A revolução urbana. Belo Horizonte: Ed. UFMG, 1999. LERUP, Lars. Building the unfinished: architecture and human action. Califórnia: Sage Publications, 1977.

LIMA, Rogério Suarez Barbosa. O antigo Leblon: uma aldeia encantada. Rio de Janeiro, 2003. Disponível em www.antigoleblon.com.br/cronicas. Acesso em 15 de agosto. 2003.

LYNCH, Kevin. The openness of open space (city sense and city design: writings and projects of Kevin Lynch). BANERJEE, Tridib e SOUTHWORTH, Michael (ed.). Cambridge: The MIT Press, 1990.

. A boa forma da cidade. Lisboa: Edições 70.

MEDEIROS, Ana Paula G. Apropriação e gestão de pátios centrais em quadras residenciais: dois exemplos cariocas. Rio de Janeiro. Dissertação de mestrado. Programa de Pós-Graduação em Urbanismo, UFRJ, 2004, mimeo.

RAFFESTIN, Claude. Por uma geografia do poder. São Paulo: Ed. Ática, 1993. SANTOS, Boaventura de Souza. Introdução a uma ciência pós-moderna. Rio de Janeiro: Graal, 1989.

SANTOS, Carlos Nelson Ferreira dos. Quando a rua vira casa. Rio de Janeiro: IBAM/FINEP, 1981.

SOUZA, Marcelo José Lopes de. O território: sobre espaço e poder. Autonomia e desenvolvimento. In: CASTRO, I. E. de; GOMES, P. C. da C. e CORRÊA, R. L. (orgs.). Geografia: conceitos e temas. Rio de Janeiro: Bertrand Brasil, 2001, p. 77116.

WHYTE, W. H. The social life of small urban open spaces. Washington D. C.: The Conservation Foundation, 1980.

ZEISEL, John. Inquiry by design. Cambridge: Cambridge University Press, 1984.

Recebido em 03 de agosto de 2009.

Aceito para publicação, em 20 de outubro de 2009. 